\title{
Evaluation of thermal and pain sensitivity in type I diabetic patients
}

\author{
Xavier Navarro, William R Kennedy
}

\begin{abstract}
Thermal sensitivity was studied in 280 type I diabetic patients and in 75 control subjects. Warm and cool thresholds, temperature sensitivity limen (difference between warm and cold thresholds, TSL), and hot and cold pain thresholds were quantitated on the skin of the index finger, hand, foot and medial calf. The diabetic group had mean values that were significantly different from controls in all variables except the pain thresholds in the upper extremity. TSL was the most sensitive parameter, being abnormal in $57,63,79$ and $78 \%$ of patients in the four skin sites tested. Hot pain sensitivity was abnormal in 37,21 , 39 and $26 \%$ of patients in the same sites. Thermal sensitivity abnormalities were more frequently observed than abnormalities in motor and sensory nerve conduction studies. Thermal tests correlated with the duration of the diabetes, although there were abnormalities at all stages of the disease. The results show that diabetic neuropathy has a variable presentation in different types of nerve fibres.
\end{abstract}

Distal, symmetric, sensory-motor polyneuropathy is one of the most frequent complications of diabetes mellitus. The spectrum of nerve involvement ranges from deficits of large nerve fibre function characterised by depressed tendon reflexes, vibration sense, propioception and touch, to small fibre dysfunction with dysaesthesia, hyperaesthesia, reduced pain and temperature perception and autonomic symptoms. ${ }^{12}$ Large fibre deficits can partially be quantified by electromyography and nerve conduction studies. With increasing frequency small nerve fibre deficits are being quantified by testing thermal sensitivity.

Temperature sense is mediated by thinlymyelinated $A \partial$ (cold) and unmyelinated $C$ (warm) nerve fibres. ${ }^{3}$ Accurate testing, requiring calibrated warm and cool stimuli, is best achieved by using Peltier elements. ${ }^{45}$ Measurement of patient response to a thermal stimulus can be accomplished quickly using the Marstock method. ${ }^{6}$ The Peltier device is also well suited for testing pain induced by hot and cold stimuli because it is safe, rapid and repeatable. ${ }^{6}$ Pain sensitivity is also conveyed by small nerve fibres from polymodal nociceptors in the skin. ${ }^{3}$
Although abnormalities of thermal sensitivity are highly prevalent in diabetes mellitus, only limited numbers of patients studied by quantitative methods have been reported, and contradictory conclusions have been reached concerning differences of the techniques applied. The aim of this study was to evaluate the prevalence of dysfunction of temperature and pain nerve fibres of the peripheral nervous system in a large group of patients with type I diabetes mellitus, to compare the usefulness of the different testing parameters used and of different sites tested, and to compare these results with those from nerve conduction studies.

\section{Material and methods \\ Subjects}

A total of 280 patients with type I diabetes mellitus, 162 women and 118 men, ranging in age from 10 to 59 years (mean 32.6) and in duration of disease from one to 49 years (mean 19.0), were evaluated. A wide range of patients were evaluated, either for diagnostic purposes or at entry into therapeutic studies, including pancreas transplantation and insulin-infusion pump. There was no selection by neurological criteria. Patient test values were compared with those from 75 normal subjects, 45 women and 30 men, aged 17 to 62 years (mean $32 \cdot 8$ ).

\section{Thermal and pain sensitivity tests}

The thermal stimulator probe was $20 \times 25 \mathrm{~mm}$ containing several coupled, multi-layered Peltier elements (Thermal Devices Inc). ${ }^{5}$ Water circulating through the thermode removed excess, current generated heat. Temperature was monitored at the probe-skin interface by a thermocouple and recorded on a chart recorder. The probe was initially set at $33^{\circ} \mathrm{C}$, then heated or cooled at $0.5^{\circ} \mathrm{C} / \mathrm{s}$. The subjects reversed the current by pressing a switch when they first detected the plate becoming warm or cool. Thermal threshold for warm (WTT) and cool (CTT) was determined as the mean of at least five reversal points during a stable record. The difference between reversal points is called the thermal sensitivity limen (TSL). ${ }^{6}$

After thermal sensitivity testing, pain thresholds were measured by warming or cooling the probe temperature at $1.5^{\circ} \mathrm{C} / \mathrm{s}$ until the subject felt pain and reversed the stimulus. The instrument was limited to excursions between $1-50^{\circ} \mathrm{C}$ to avoid skin damage in hyperaesthesic individuals. Pain thresholds by hot and cold stimuli (HPT and CPT) were determined as the average of three acceptable trials. 
Table 1 Results of tests for temperature and pain sensitivity in control and diabetic subjects

\begin{tabular}{|c|c|c|c|c|c|c|}
\hline \multirow[t]{2}{*}{. } & \multicolumn{3}{|c|}{ Controls $(n=75)$} & \multicolumn{3}{|c|}{ Diabetics $(n=280)$} \\
\hline & $x$ & $S D$ & P95 & $x$ & $S D$ & \\
\hline $\begin{array}{l}\text { TSL index } \\
\text { TSL hand } \\
\text { TSL foot } \\
\text { TSL calf }\end{array}$ & $\begin{array}{l}2 \cdot 9 \\
2 \cdot 4 \\
6 \cdot 2 \\
6 \cdot 7\end{array}$ & $\begin{array}{l}1 \cdot 3 \\
0 \cdot 8 \\
2 \cdot 2 \\
2 \cdot 1\end{array}$ & $\begin{array}{l}4 \cdot 8 \\
3 \cdot 5 \\
8 \cdot 0 \\
9 \cdot 0\end{array}$ & $\begin{array}{r}8 \cdot 1 \\
7 \cdot 2 \\
21 \cdot 2 \\
20 \cdot 3\end{array}$ & $\begin{array}{r}7 \cdot 5 \\
7 \cdot 2 \\
13 \cdot 8 \\
12 \cdot 8\end{array}$ & $\begin{array}{l}\star \star \\
\star \star \\
\star \star \\
\star \star\end{array}$ \\
\hline $\begin{array}{l}\text { WTT index } \\
\text { WTT hand } \\
\text { WTT foot } \\
\text { WTT calf }\end{array}$ & $\begin{array}{l}35 \cdot 2 \\
35 \cdot 4 \\
37 \cdot 7 \\
38 \cdot 3\end{array}$ & $\begin{array}{l}1.5 \\
1 \cdot 1 \\
1.8 \\
1.9\end{array}$ & $\begin{array}{l}37 \cdot 2 \\
37 \cdot 2 \\
40 \cdot 0 \\
41 \cdot 0\end{array}$ & $\begin{array}{l}38 \cdot 8 \\
37 \cdot 9 \\
42 \cdot 6 \\
42 \cdot 4\end{array}$ & $\begin{array}{l}4 \cdot 2 \\
3 \cdot 5 \\
5 \cdot 0 \\
4 \cdot 4\end{array}$ & $\begin{array}{l}\star \star \\
\star \star \\
\star \star \\
\star \star\end{array}$ \\
\hline $\begin{array}{l}\text { CTT index } \\
\text { CTT hand } \\
\text { CTT foot } \\
\text { CTT calf }\end{array}$ & $\begin{array}{l}32 \cdot 3 \\
33 \cdot 0 \\
31 \cdot 4 \\
31 \cdot 5\end{array}$ & $\begin{array}{l}1.5 \\
1.2 \\
1.8 \\
1.7\end{array}$ & $\begin{array}{l}30 \cdot 5 \\
31 \cdot 5 \\
29 \cdot 0 \\
29 \cdot 0\end{array}$ & $\begin{array}{l}30 \cdot 7 \\
30 \cdot 7 \\
21 \cdot 3 \\
21 \cdot 9\end{array}$ & $\begin{array}{r}4 \cdot 7 \\
5 \cdot 0 \\
10 \cdot 1 \\
10 \cdot 2\end{array}$ & $\begin{array}{l}\star \\
\star \star \\
\star \star \\
\star \star\end{array}$ \\
\hline $\begin{array}{l}\text { HPT index } \\
\text { HPT hand } \\
\text { HPT foot } \\
\text { HPT calf }\end{array}$ & $\begin{array}{l}44 \cdot 8 \\
43 \cdot 9 \\
43 \cdot 9 \\
45 \cdot 1\end{array}$ & $\begin{array}{l}3 \cdot 2 \\
2 \cdot 9 \\
2 \cdot 8 \\
2 \cdot 5\end{array}$ & $\begin{array}{l}48 \cdot 5 \\
47 \cdot 8 \\
48 \cdot 0 \\
48 \cdot 5\end{array}$ & $\begin{array}{l}46 \cdot 9 \\
44 \cdot 8 \\
46 \cdot 6 \\
46 \cdot 6\end{array}$ & $\begin{array}{l}2 \cdot 8 \\
3 \cdot 3 \\
3 \cdot 2 \\
2 \cdot 7\end{array}$ & $\begin{array}{l}\star \star \\
\star \star \\
\star \star\end{array}$ \\
\hline $\begin{array}{l}\text { CPT index } \\
\text { CPT hand } \\
\text { CPT foot } \\
\text { CPT calf }\end{array}$ & $\begin{array}{l}10 \cdot 6 \\
11.8 \\
12.0 \\
11.9\end{array}$ & $\begin{array}{l}8 \cdot 9 \\
8 \cdot 5 \\
8 \cdot 9 \\
9 \cdot 5\end{array}$ & $\begin{array}{l}1 \cdot 0 \\
1.0 \\
1.0 \\
1.0\end{array}$ & $\begin{array}{r}8 \cdot 1 \\
12 \cdot 1 \\
7 \cdot 7 \\
8 \cdot 3\end{array}$ & $\begin{array}{l}8 \cdot 1 \\
8 \cdot 4 \\
8 \cdot 9 \\
8 \cdot 6\end{array}$ & 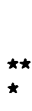 \\
\hline
\end{tabular}

${ }^{\star} \mathrm{p}<0.01 ;{ }^{\star \star} \mathrm{p}<0.0005$ with respect to controls.

Thermal and pain sensitivity were tested in each subject on four skin areas: dorsum of the index finger, dorsum of the hand (over the first dorsal interosseus muscle), lateral dorsal foot (over the extensor digitorum brevis muscle), and medial calf. Testing at the four sites required 20 to 25 minutes. Thermal tests were conducted in a room maintained near $22^{\circ} \mathrm{C}$.

\section{Nerve conduction studies}

Motor nerve conduction velocity (NCV) was measured for one ulnar, median, peroneal and tibial nerve. The evoked muscle action potential (MAP) was recorded from hypothenar, thenar, extensor digitorum brevis and abductor digiti quinti muscles, respectively. Values for ulnar and median nerves, and those for peroneal and tibial nerves were averaged to facilitate comparisons with other parameters. Orthodromic sensory nerve conduction was measured in the median and sural nerves. Nerve conduction was performed in the same extremities used for thermal tests. The normal limits (P95\% values) determined in our laboratory for healthy subjects are: ulnar and

Table 2 Relative frequencies of abnormal tests in the diabetic patients studied

\begin{tabular}{|c|c|c|c|c|c|c|c|}
\hline \multirow{2}{*}{$\begin{array}{l}\text { Site } \\
\text { tested }\end{array}$} & \multirow[b]{2}{*}{ Parameter } & \multicolumn{6}{|c|}{ Abnormalities } \\
\hline & & $n$ & $\%$ & $n$ & $\%$ & $n$ & $\%$ \\
\hline Index & $\begin{array}{l}\text { WTT } \\
\text { CTT } \\
\text { TSL } \\
\text { HPT }\end{array}$ & $\begin{array}{r}147 \\
77 \\
160 \\
105\end{array}$ & $\begin{array}{l}52 \cdot 5 \\
27 \cdot 5 \\
57 \cdot 1 \\
37 \cdot 5\end{array}$ & 181 & $64 \cdot 6$ & 207 & 73.9 \\
\hline Hand & $\begin{array}{l}\text { WTT } \\
\text { CTT } \\
\text { TSL } \\
\text { HPT }\end{array}$ & $\begin{array}{r}114 \\
102 \\
177 \\
58\end{array}$ & $\begin{array}{l}40 \cdot 7 \\
36 \cdot 4 \\
63 \cdot 2 \\
20 \cdot 7\end{array}$ & 190 & $67 \cdot 9$ & 197 & $70 \cdot 4$ \\
\hline Foot & $\begin{array}{l}\text { WTT } \\
\text { CTT } \\
\text { TSL } \\
\text { HPT }\end{array}$ & $\begin{array}{r}148 \\
170 \\
198 \\
98\end{array}$ & $\begin{array}{l}59 \cdot 2 \\
68 \cdot 0 \\
79 \cdot 2 \\
39 \cdot 2\end{array}$ & 203 & $81 \cdot 2$ & 205 & $82 \cdot 0$ \\
\hline Calf & $\begin{array}{l}\text { WTT } \\
\text { CTT } \\
\text { TSL } \\
\text { HPT }\end{array}$ & $\begin{array}{r}135 \\
162 \\
194 \\
64\end{array}$ & $\begin{array}{l}54 \cdot 0 \\
64 \cdot 8 \\
77 \cdot 6 \\
25 \cdot 6\end{array}$ & 197 & $78 \cdot 8$ & 198 & $79 \cdot 2$ \\
\hline
\end{tabular}

median NCV $48 \mathrm{~m} / \mathrm{s}$; MAP of thenar and hypothenar eminence $5 \mathrm{mv}$; peroneal and tibial nerve NCV $40 \mathrm{~m} / \mathrm{s}$; MAP of extensor digitorum brevis and abductor digiti quinti 3 mv; median and sural nerve distal sensory conduction latency $3.5 \mathrm{~ms}$ and NAP 10 and 5 uv respectively.

\section{Clinical evaluation}

The clinical presence of neuropathy was assessed by the same investigator (WRK) in 168 patients. Selected items of the neurological examination were scored according to a previously defined protocol, ${ }^{7}$ including tendon reflexes, motor and sensory functions in the upper and lower extremities. Each feature of the examination was classified as normal, mild, moderate or severely abnormal.

\section{Statistical analysis}

Data are expressed as arithmetical mean and SD. The lower (or upper) limit of normal values for thermal and pain tests was established as the 95 percentile (P95) of the control subjects. Comparisons between groups were made by the Student's $t$ test for unpaired samples, and relationships between variables by linear regression and correlation analysis.

\section{Results}

Thermal sensitivity

The mean values for the control subjects are shown in table 1 . TSL averaged $2.9^{\circ} \mathrm{C}$ (range $1 \cdot 0-5 \cdot 7)$ on the index finger, $2 \cdot 4^{\circ} \mathrm{C}(1 \cdot 0-4 \cdot 0)$ on the hand, $6.2^{\circ} \mathrm{C}(2 \cdot 7-12.0)$ on the foot, and $6 \cdot 7^{\circ} \mathrm{C}(2 \cdot 8-12 \cdot 0)$ on the calf. Measurements from the finger were usually less satisfactory than from the hand, because the area of contact between the flat probe surface and the finger was variable. The same applies to measurements performed in the big toe. Data from the toe are not presented because in diabetic patients the toe was too often insensitive to thermal stimuli for practical use. The TSL measured on the four different areas of the skin correlated well in the control subjects (correlation coefficients ranged between 0.30 and $0.64, p<0.05$ ).

There were no significant correlations between any of the thermal sensitivity variables and age in control subjects $(r=0.01$ to 0.21$)$. Female controls had on average slightly higher sensitivity than males, but the differences were not significant, except for WTT in the dorsum of the hand and HPT in the calf. Intraindividual variability was low; the coefficient of variation for five control subjects tested 10 times, with at least one day interval, was between eight and $15 \%$. Variability of the TSL on repeated occasions in 10 normal and 10 diabetic subjects tested twice within a one month interval showed a high correlation $(r=$ $0.97, \mathrm{p}<0.0001$ ).

Thermal sensitivity values for the diabetic patients are shown in table 1. All the parameters recorded were significantly different from those of the control group ( $p<$ 0.01 to $p<0.0001$ ). Table 2 shows the extent of abnormalities detected for each of the 
Table 3 Relation between temperature and pain sensitivity and motor and sensory nerve conduction (including nerve conduction velocity or distal latency and amplitude of the evoked action potential) in the diabetic patients

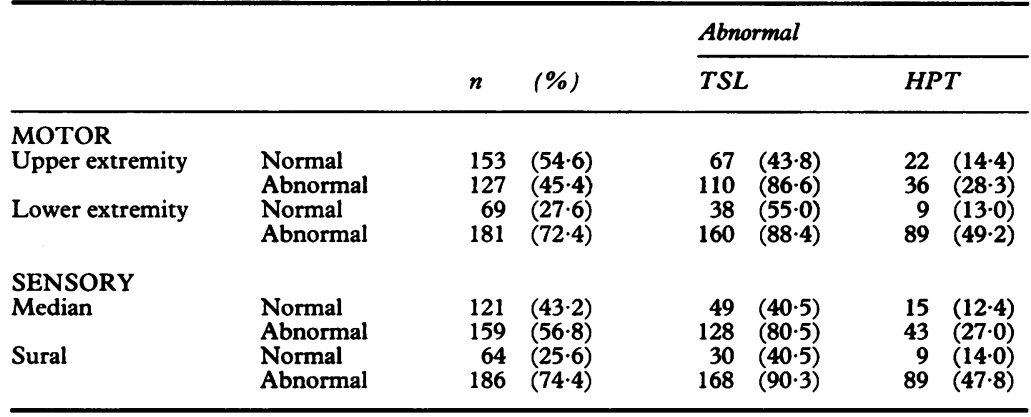

parameters. For each skin site tested, the TSL was the most frequently abnormal value among the diabetic patients. Fewer tests were done on the lower extremity ( 250 patients) because of amputations or local lesions. As in the control subjects the results from different skin sites of patients correlated well. TSL was normal on both hand and foot in only 39 patients.

Comparison of warm and cold thresholds showed good correlation in all the sites tested $(\mathrm{r}=0.44$ to $0.60, \mathrm{p}<0.001)$. However, there were discrepancies in individual patients; CTT was abnormal slightly more often than WTT in the lower extremity, but not in the upper extremity (table 2).

\section{Pain sensitivity}

The HPT averaged $43.9^{\circ} \mathrm{C}$ for the hand and foot in control subjects and slightly higher for the index finger $\left(44.8^{\circ} \mathrm{C}\right)$ and calf $\left(45.1^{\circ} \mathrm{C}\right)$ (table 1). Cold pain sensation is known to be more subject to variation and difficult to evaluate. ${ }^{6} \mathrm{CPT}$ was quite variable in the control subjects, the lower limit being equal to the minimum temperature that the stimulator was allowed to reach $\left(1^{\circ} \mathrm{C}\right)$, thus it was less useful to detect abnormalities in the patients. HPT was less variable between subjects, although the upper normal limit was close to the maximum

Figure Relation of thermal sensitivity limen (TSL), and hot pain threshold (HPT) with the duration of diabetes mellitus.

$\star=p<0.0001$
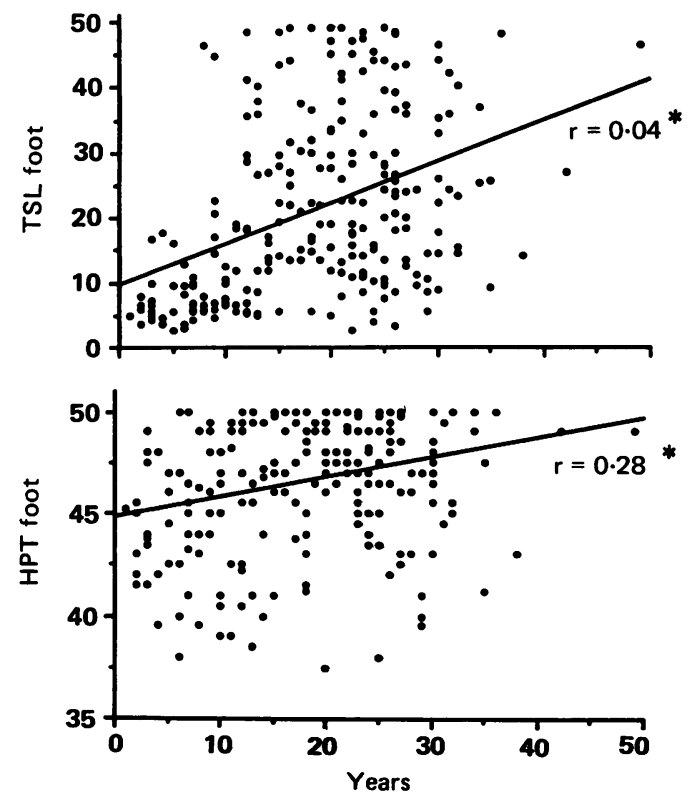

temperature stimulus allowed. Neither age nor sex of the subjects influenced HPT. Again, there were significant correlations between results obtained in different sites of the same subjects $(r=0.48$ to $0.74, p<0.001)$.

The mean values in the diabetic group were significantly different from those of control subjects, except for the CPT for the index finger and hand and the HPT for the hand. The HPT was impaired in a lower proportion of diabetic patients than temperature thresholds or the limen in all sites tested (table 2). HPT was abnormal in only a few patients who had a normal TSL (seven in the hand, two in the foot). Results of HPT in different sites were also correlated in the diabetics. There were very few hyperalgesic responses; only four patients in the hand and three in the foot had a HPT that was below the lower limit of normal for controls, all of these had normal TSL values.

\section{Relationship to nerve conduction}

Nerve conduction data of diabetic patients showed significant correlations with TSL and HPT values, but there were different patterns of involvement. The majority of patients with abnormal motor or sensory nerve conduction also had impaired thermal sensitivity in the hand or the foot (table 3). Of importance, approximately half of the patients with nerve conduction within normal limits had abnormal TSL. In fact, TSL was the most frequently abnormal neurophysiological parameter in this group of diabetic patients.

\section{Relation with clinical observations}

TSL values, but not HPT correlated significantly with the duration of diabetes (fig). TSL was abnormal in at least one of the areas tested in seven of 20 patients tested with less than five years duration, while it was abnormal in all 28 patients with diabetes longer than 30 years. However, in all comparisons the correlation coefficients were relatively low $(0.05$ to 0.40 ), indicating that small nerve fibres may be involved at any stage of the disease.

Of the 168 patients clinically evaluated by the same investigator, 46 had no evidence of neuropathy and 122 had a variable degree of severity of neuropathy (table 4). Among the 46 patients who were normal on clinical examination, 26 had abnormalities in TSL in the hand or the foot, while only 15 had abnormalities in the nerve conduction studies, and nine of HPT. On the other hand, no patients with moderate or severely abnormal examination had normal TSL, three had normal nerve conduction tests, and 35 had normal HPT values.

\section{Discussion}

Thermal sensitivity was abnormal in a high proportion of this large group of type I diabetic patients; a higher percentage than abnormalities found on the nerve conduction parameters. Thermal sensitivity was also abnormal almost twice as often as suspected from clinical findings. ${ }^{8}$ Other studies have also found that diabetic patients often have 
Table 4 Relation between temperature and pain sensitivity in the hand and the foot and the neurological examination

\begin{tabular}{|c|c|c|c|c|c|c|c|c|c|}
\hline \multirow{3}{*}{$\begin{array}{l}E X A M \\
\text { Normal } \\
\text { Mild } \\
\text { Moderate } \\
\text { Severe }\end{array}$} & \multirow{3}{*}{$\begin{array}{l}n \\
46 \\
28 \\
37 \\
57\end{array}$} & \multirow{3}{*}{$\begin{array}{l}(\%) \\
(27 \cdot 4) \\
(16 \cdot 7) \\
(22 \cdot 0) \\
(33 \cdot 9)\end{array}$} & \multicolumn{7}{|c|}{ Abnormal } \\
\hline & & & \multicolumn{2}{|c|}{ TSL hand } & $T S L$ foot & \multicolumn{2}{|c|}{ HPT hand } & \multicolumn{2}{|c|}{ HPT foot } \\
\hline & & & $\begin{array}{l}15 \\
12 \\
28 \\
51\end{array}$ & $\begin{array}{l}(32 \cdot 6) \\
(42 \cdot 9) \\
(75 \cdot 7) \\
(89 \cdot 5)\end{array}$ & $\begin{array}{ll}21 & (45 \cdot 6) \\
21 & (75 \cdot 0) \\
36 & (100)^{\star} \\
51 & (100)^{\star}\end{array}$ & $\begin{array}{r}6 \\
6 \\
9 \\
16\end{array}$ & $\begin{array}{l}(13 \cdot 0) \\
(21 \cdot 4) \\
(24 \cdot 3) \\
(28 \cdot 1)\end{array}$ & $\begin{array}{r}8 \\
10 \\
13 \\
39\end{array}$ & $\begin{array}{l}(17 \cdot 4) \\
(35 \cdot 7) \\
(36 \cdot 1)^{\star} \\
(76 \cdot 5)^{\star}\end{array}$ \\
\hline
\end{tabular}

«Amputations, plaster casts, etc prevented testing the foot in some patients.

impaired thermal thresholds. ${ }^{9-12}$ Thermal abnormalities are found with higher prevalence in diabetic patients who have other signs of peripheral neuropathy. ${ }^{910}$ The impairment is still greater for those with clinical findings of small nerve fibre disease, ${ }^{1013}$ painful neuropathy ${ }^{1415}$ or foot ulcerations. ${ }^{16}$ The percentage of abnormalities detected is dependent upon the characteristics of the diabetic population examined and the device utilised.

Thermal sensitivity was abnormal more frequently than any of the motor or sensory nerve conduction studies. In fact, TSL was abnormal in about half of the patients in whom the nerve conduction measurements were normal. Others have also shown that a deficit of thermal sensation can exist in the presence of normal nerve conduction. ${ }^{113}$ However, the converse has also been found as the medial plantar nerve action potential was reported to be reduced or absent in patients with normal thermal sensation. ${ }^{17}$ These findings confirm the variable degrees of abnormalities that exist in the different types of nerve fibres that are responsible for the clinical signs and symptoms observed in patients with diabetic neuropathy. ${ }^{2}$

The abnormal TSL values can be attributed to dysfunction of peripheral small nerve fibres. ${ }^{18}$ Our findings indicate that thinly myelinated and unmyelinated nerve fibres are involved in almost all patients with type I diabetes mellitus of long duration. This conclusion is consistent with neuropathological observations that show more severe and early loss of small fibres than of large myelinated fibres. ${ }^{19-21}$ It is also supported by the good correlation of thermal sensitivity with function tests that evaluate sympathetic ${ }^{8}$ or parasympathetic unmyelinated axons. ${ }^{22}$ Temperature sensitivity abnormalities were frequent at all stages of the evolution of diabetes, although they tended to increase with longer duration of disease. Ziegler et $a l^{23}$ showed evidence of abnormalities in temperature sensation in a quarter of newly diagnosed patients, preceeding impairment of large nerve fibre function. It is also worth noting that thermal sensory fibre function does not show a clear correlation with the degree of glucose control achieved in diabetic patients. ${ }^{2324}$

The higher frequency of abnormalities in the lower than in the upper extremity and their good correlation are consistent with a length dependent pathology in diabetic neuropathy. ${ }^{21}$ This is consistent with the finding that abnormalities of facial thermal sensibility are less frequent than on the extremities. ${ }^{16} \mathrm{We}$ routinely tested four sites to quantitate the evolution of a progressive, contripetal deficit. However, the comparisons between areas of one extremity were not conclusive, probably because of differences in the thermal sensitivity threshold due to great variation in density of thermal receptors between areas. ${ }^{3}$

One of the claimed disadvantages of thermal sensitivity tests is the inter-individual variability of results. ${ }^{25}$ While such variation may be large, intra-individual variation is small with the Marstock design, ${ }^{6}$ and comparable to the coefficient of variation obtained with forced-choice methods, ${ }^{96}$ although the latter may be improved by using automated methods. ${ }^{27}$ In our experience, the variation of repeated tests by the Marstock method in the same individuals is acceptable, provided that the subjects are given clear instructions and the test is performed under careful, standardised conditions. Values for our control group are similar to those found by other author ${ }^{6}{ }^{10}$ using the same technique in similar but not identical sites. For comparisons of results between laboratories, the variations in stimulator size, contact pressure of the thermal head, baseline temperature, rate of change and duration of stimuli, and thermal sensitivity of different sites must be considered. ${ }^{28}$

The difference between the cold and warm threshold values (TSL) is considered to be the most sensitive measurement of the Marstock method. ${ }^{6}$ The CTT and WTT have been shown to become abnormal in parallel in diabetic ${ }^{8}$ and in uraemic patients. ${ }^{29}$ However, others found cold sensation thresholds to be abnormal more often that warm thresholds or even more abnormal than the TSL, ${ }^{1223}$ but the reverse has also been reported. ${ }^{16}$ The sensitivity of the different devices in detecting abnormalities of cooling versus abnormality of warming sense is an important but yet unmeasured variable of published reports. In our patients the cold threshold was slightly more often abnormal than the warm threshold, but the TSL was more sensitive than either threshold. Our results suggest that small unmyelinated (warm) and thinly myelinated (cold) axons are involved similarly in diabetic neuropathy. We recommend analysis of both thresholds plus the TSL for detection in the occasional patient of differential involvement of these nerve fibres.

Measurement of pain sensation thresholds elicited by thermal or electrical stimuli is considered more suitable than by mechanical methods, ${ }^{30}$ which have lower accuracy and sensitivity. ${ }^{3132}$ Measurement of CPT was not useful to detect abnormalities in patients, and we have discontinued this part of the test for regular use. HPT was abnormal in almost one half of our patients, a slightly lower percentage than found by Ohtomo et al ${ }^{33}$ using hot radiant stimuli. HPT was not as sensitive as TSL for detecting abnormalities, but it did contribute information about a different population of small nerve fibres. HPT showed only a weak relationship to the TSL, in part due to individual variability in psychological perception to pain, and perhaps also because hot pain 
is mediated by a different pathway than thermal sensation. ${ }^{34}$

In conclusion, quantitative thermal sensory testing is a sensitive method to study small axon function. The accuracy of the Marstock method and the short testing time required make it practical to use in the clinical evaluation of patients. Our results provide further support of the practicality of establishing a profile of involvement of the different nerve fibre types in each patient to document changes in the degree of the neuropathy in therapeutic trials.

The authors thank J Spiry, L Balloge and F Sahinen for their excellent technical assistance. This work was supported in par by a NIH grant RO1 NS 26348 and NIH Clinical Research Center Grant (RR-400).

1 Rundles RW. Diabetic neuropathy: a general review with report of 125 cases. Medicine 1945:24:111-60.

2 Brown MJ, Asbury AK. Diabetic neuropathy. Ann Neurol 1984;15:2-12.

3 Light AR, Perl ER. Peripheral sensory systems. In: Dyck PJ Thomas PK, Lambert EH, Bunge R, eds. Peripheral Neuropathy. Philadelphia: Saunders, 1984:210-30.

4 Kenshalo DR, Bergen DC. A device to measure cutaneous remperature sensitivity in humans and subhuman species. J Appl Physiol 1975;39:1038-40.

5 Wilcox GL, Giesler GJ. An instrument using a multiple layer Peltier device to change skin temperature rapidly Brain Res Bull 1984;12:143-6.

6 Fruhstorfer H, Lindblom U, Schmidt WG. Method for quantitative estimation of thermal thresholds in patients. $J$ Neurol Neurosurg Psychiatry 1976;391071-5.

7 Kennedy WR, Navarro X, Sakuta M, Mandell H, Knox CK, Sutherland DER. Physiological and clinical correlates of cardiorespiratory reflexes in diabetes mellitus. Diabetes Cardiorespiratory reflex

8 Navarro X, Kennedy WR, Fries TJ. Small nerve fiber dysfunction in diabetic neuropathy. Muscle Nerve 1989;12:498-507.

9 Bertelsmann FW, Heimans JJ, Weber EJM, Van der Veen EA, Schouten JA. Thermal discrimination thresholds in normal subjects and in patients with diabetic neuropathy. $J$ Neurol Neurosurg Psychiatry 1985;48:686-90.

10 Guy RJC, Clark CA, Malcolm PN, Watkins PJ. Evaluation of thermal and vibration sensation in diabetic neuropathy. Diabetologia 1985;28:131-7.

11 Jamal GA, Weir AI, Hansen S, Ballantyne JP. An improved automated method for the measurement of thermal thresholds. 2 Patients with peripheral neuropathy. $J$ Neurol Neurosurg Psychiatry 1985;48:361-6.

12 Claus D, Hilz MJ, Hummer I, Neundorfer B. Methods of measurement of thermal thresholds. Acta Neurol Scand 1987;76:288-96.

13 Jamal GA, Hansen S, Weir AI, Ballantyne P. The neurophysiologic investigation of small fiber neuropathies. Muscle Nerve 1987;10:537-45.
14 Heimans JJ, Bertelsmann RW, Van Rooy JCGM. Large and small nerve fiber function in painful diabetic neuropathy. $J$ Neurol Sci 1986:74:1-9.

15 Ziegler D, Mayer P, Wiefels K, Gries FA. Assessment of small and large fiber function in long-term type $I$ (insulindependent) diabetic patients with and without painful neuropathy. Pain 1988;34:1-10.

16 Ali Z, Carroll M, Robertson KP, Fowler CJ. The extent of small fibre sensory neuropathy in diabetics with plantar foot ulceration. J Neurol Neurosurg Psychiatry 1989; 52:94-8.

17 Levy-DM, Abraham RR, Abraham RM. Improved detection of early diabetic neuropathy using studies of the tion of early diabetic neuropathy using studies of the

18 Dyck PJ, Karnes JL, Daube J, O'Brien PC, Service FJ. Clinical and neuropathological criteria for the diagnosis and staging of diabetic polyneuropathy. Brain 1985; and staging

19 Behse F, Buchthal F, Carlsen F. Nerve biopsy and conduction studies in diabetic neuropathy. $J$ Neurol Neurosurg Psychiatry 1977;40:1072-82.

20 Bischoff A. Morphology of diabetic neuropathy. Horm Metab Res Suppl 1980;9:18-28.

21 Said G, Slama G, Selva J. Progressive centripetal degeneration of axons in small fiber diabetic polyneuropthy. Brain 1983;106:791-807.

22 Lanting P, Heimans JJ, Reulen JP, Nauta J, Van der Veen EA. Pupillary light reflex and quantitative sensory and motor neural function tests in diabetic patients. $J$ Neurol 1988;235:245-7.

23 Ziegler D, Mayer P, Gries FA. Evaluation of thermal, pain, and vibration sensation thresholds in newly diagnosed Type I diabetic patients. J Neurol Neurosurg Psychiatry 1988;51:1420-24.

24 Bertelsmann FW, Heimans JJ, Van Rooy JC, Popp-Snijders $\mathrm{C}$, Van der Veen EA. Peripheral nerve function in relation to quality of metabolic control in diabetes. $J$ Neurol 1987;234:334-6.

25 Fagius J, Wahren LK. Variability of sensory threshold determination in clinical use. $J$ Neurol Sci 1981;51:11-27.

26 Dyck PJ, Karnes J, O'Brien PC, Zimmerman IR. Detection thresholds of cutaneous sensation in humans. In: Dyck PJ, Thomas PK, Lambert EH, Bunge R, eds. Peripheral Neuropathy. Philadelphia, Saunders, 1984:1103-38.

27 Jamal GA, Hansen S, Weir AI, Ballantyne P. An improved automated method for the measurement of thermal thresholds. 1. Normal subjects. J Neurol Neurosurg Psychiatry 1985;48:354-60.

28 Stevens JC, Marks LE, Simonson DC. Regional sensitivity and spatial summation in the warmth sense. Physiol Behav 1974;13:825-36.

29 Lindblom U, Tegner R. Thermal sensitivity in uremic neuropathy. Acta Neurol Scand 1985;71:290-4.

30 Procacci P, Zoppi M, Maresca M. Experimental pain in man. Pain 1979;6:123-40.

31 LeQuesne PM, Fowler CJ. A study of pain threshold in diabetics with neuropathic foot lesions. I Neurol Neurosurg Psychiatry 1986;49:1191-4.

32 Merskey H, Evans PR. Variations in pain complaint threshold in psychiatric and neurological patients with pain. Pain 1975;1:73-9.

33 Ohtomo $H$, Kogure $K$, Izumiyama $M$, et al Clinical application of thermal pain meter (NY-5) in patients with diabetes mellitus. In: Goto $\mathrm{Y}$, Horiuchi $\mathrm{A}$, Kogure $\mathrm{K}$, eds. diabetes mellitus. In: Goto Y, Horiuchi A, Kogure K, eds. Diabetic

34 Konietzny F. Peripheral neural correlates of temperature sensations in man. Human Neurobiol 1984;3:21-32. 